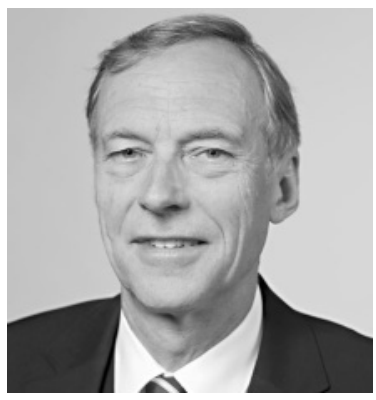

Arndt Bode

Hauptherausgeber

\title{
Tempora mutantur
}

Hermann Engesser hat sich im Editorial von Heft 3/2017 unter der Überschrift "In eigener Sache" von Ihnen nach 22 Jahren der Verantwortung im Verlag für das Informatik Spektrum als Chefredakteur verabschiedet und diese Aufgabe an Peter Pagel, seinen Nachfolger als Chefredakteur übergeben. "In eigener Sache" war natürlich maßlos untertrieben, denn das Informatik Spektrum und die Informatik waren und sind für Hermann Engesser keine neutrale "Sache", sondern ein Herzensanliegen.

Ich habe Hermann Engesser 1985 beim Bl-Verlag Mannheim kennengelernt, wo ich als junger Informatiker neu in den Herausgeberkreis der Reihe Informatik der BI Hochschultaschenbücher aufgenommen wurde und er, zunächst als Lektor, für die Reihe tätig war. Obschon kein Informatiker, war Hermann Engesser auch für anspruchsvolle Fachthemen der Informatik immer ansprechbar und er hat immer den Eindruck vermittelt, dass ihn diese neue Wissenschaftsrichtung inhaltlich fasziniert. Er ist eben ein Intellektueller im besten Sinne des Wortes, der an der "Sache" Informatik höchst interessiert war und ist.

Von sich selbst sagt Engesser, er sei „mit der Informatik gewachsen", was für ihn sicher ebenso zutreffend ist, wie auch für alle Informatiker der ersten - und zweiten - Stunde, denn der stete rasche fachliche Wandel dieser Wissenschaft und ihrer Anwendungen erfordert ja autodidaktische Kompetenz.

Fachliches Interesse an und Verständnis für Inhalte der Forschung, Lehre und Anwendung der Informatik waren aber nicht die einzigen Eigenschaften von Hermann Engesser. Sein enges Verhältnis zur Gesellschaft für Informatik und deren Fachgliederungen, aber auch zur Informatik allgemein, hat er durch zahllose Teilnahmen an Workshops, Kongressen und sonstigen Fachveranstaltungen gepflegt und damit hervorragende Kenntnis des "who is who" der Informatik entwickelt. So ist es ihm gelungen, stets die Vorschläge für fachliche Beiträge aus den Reihen des Herausgebergremiums durch originelle und lesenswerte zusätzliche Artikel zu ergänzen.

Das Anliegen von Hermann Engesser ging ganz sicher über die Aufgabe „70 Seiten alle 2 Monate" hinaus. Er hat sich auch als wesentlicher Akteur verstanden in dem Anliegen, das Informatik Spektrum zum Organ aller deutschsprachiger Informatik-Fachgesellschaften zu entwickeln. Vor etwa 15 Jahren war sein größter Erfolg, die schweizerische Fachorganisation SI für das Informatik Spektrum zu gewinnen. So war es auch kein Wunder, dass Hermann Engesser bereit war, das neue Team von Chefredakteur Peter Pagel und Redakteurin Sybille Thelen nach seinem Eintritt in die passive Altersteilzeit im Juli 2017 für ein weiteres Jahr inhaltlich zu begleiten. Mit diesem Heft des Informatik Spektrums endet nun auch dieser Zeitabschnitt, der den reibungslosen Übergang bestens ermöglicht hat. Ich möchte deshalb persönlich für mehr als 30 Jahre konstruktive Zusammenarbeit und Freundschaft danken. Die Informatik und mit ihr die Gl verlieren einen Freund, aber nicht ganz, denn Hermann Engesser bleibt dem Informatik Spektrum erhalten, er wird künftig über Neuerscheinungen in der Informatik berichten. Ich freue mich schon auf seine Rezensionen!

Das vorliegende Heft behandelt sehr unterschiedliche Bereiche der Informatik, von der IT-Organisation bis zur Grundschulausbildung. Markus Weiß et al. berichten über "IT-gestützte Standortauswahl bei Niederlassungen“. Florian Stuhl et al. geben eine Übersicht zu "Datenmarktplätzen in verschiedenen Forschungsdisziplinen”. Das „Anforderungsmanagement in großen IT-Projekten" ist Thema von Kai Engel et al. Aus dem Bereich der Rechnerarchitektur stammt der Beitrag "Erfahrungen beim Aufbau von großen Clustern aus Einplatinencomputern für Forschung und Lehre" von Christian Baun et al. Die "Informatik in der Grundschule" ist das Thema von Ute Schmid et al. Diese Beiträge und die üblichen Rubriken bereiten Ihnen hoffentlich ein sommerliches Lesevergnügen.

\section{Arndt Bode}

DOI $10.1007 /$ s00287-018-1106-1 